\title{
Sheep and Fasciola hepatica in Europe: the GLOWORM experience
}

Laura Rinaldi ${ }^{1}$, Annibale Biggeri², Vincenzo Musella ${ }^{3}$, Theo de Waal ${ }^{4}$, Hubertus Hertzberg 5 , Fabien Mavrot ${ }^{6}$, Paul R. Torgerson ${ }^{6}$, Nikolaos Selemetas ${ }^{4}$, Tom Coll ${ }^{7}$, Antonio Bosco ${ }^{1}$, Laura Grisotto $^{2}$, Giuseppe Cringoli ${ }^{1}$, Dolores Catelan ${ }^{2}$

${ }^{1}$ Department of Veterinary Medicine and Animal Productions, University of Naples Federico II, Naples, Italy, CREMOPAR Campania Region, Naples, Italy; ${ }^{2}$ Department of Statistics, Informatics and Applications "G. Parenti", University of Florence, Florence, Italy; ${ }^{3}$ Department of Health Sciences, University "Magna Grocia" of Catanzaro, Catanzaro, Italy; ${ }^{4}$ UCD School of Veterinary Medicine, University College Dublin, Dublin, Ireland; ${ }^{5}$ Institute of Parasitology, Vetsuisse Faculty, University of Zurich, Zurich, Switzerland; ${ }^{6}$ Section of Epidemiology, Vetsuisse Faculty, University of Zurich, Zurich, Switzerland; ${ }^{7}$ Teagasc, Mohill, Co Leitrim, Ireland

\begin{abstract}
Fasciola hepatica infection challenges health, welfare and productivity of small ruminants throughout the world. The distribution of $F$. hepatica in sheep in Europe is usually scattered and studies are generally concerned with a single area making it difficult to compare results from different environments, climates and management regimes. In order to elucidate the current scenario in terms of prevalence and intensity of $F$. hepatica infection in sheep farms across Europe, a standardized cross-sectional survey was conducted in three pilot areas in Ireland, Switzerland and Italy, all part of the EU funded GLOWORM project. Two consecutive field surveys (in 2012 and 2013) were conducted in the three countries in the same period (August-October) in 361 sheep farms in total. Harmonized procedures (from farm to laboratory) based on pooled samples and the highly sensitive and accurate, diagnostic FLOTAC technique were used. The georeferenced parasitological results were modelled (at the pilot area level) following a Bayesian geostatistical approach with correction for preferential sampling and accounting for climatic and environmental covariates. The observed F. hepatica prevalence rates did not differ between the two study years in any of the three pilot areas, but they did vary between the countries showing high values in Ireland $(61.6 \%)$ compared to Italy $(7.9 \%)$ and Switzerland $(4.0 \%)$. Spatial patterns of $F$. hepatica distribution were detected by the Bayesian geostatistical approach in Ireland with a high risk of infection in the south-western part of the pilot area there. The latent factor analysis highlighted the importance of year-to-year variation of mean temperature, rainfall and seasonality within a country, while long-term trends of temperature and rainfall dominated between countries with respect to prevalence of infection.
\end{abstract}

Keywords: Fasciola hepatica, sheep, geographical information systems, Bayesian modelling, Europe.

\section{Introduction}

Sheep farming has a prominent role in the sustainability of rural communities around the world (Park and Haenlein, 2006), as well as being socially, economically and politically highly significant at national and international levels, like all livestock species (Morgan et al., 2013). In the European Union (EU), there are currently around 98 million sheep (FAOSTAT, 2012). Efficient sheep livestock production is

\footnotetext{
Laura Rinaldi

Unit of Parasitology and Parasitic Diseases

Department of Veterinary Medicine and Animal Productions

University of Naples Federico II

Via della Veterinaria 1, 80137 Naples, Italy

Tel/Fax +39 081 253-6283

E-mail: lrinaldi@unina.it
}

crucial to meet the increasing demands of meat and dairy products, especially in areas in which land is not arable (Chiotti and Johnston, 1995). However, several factors affect the productivity of the ovine sector in the $\mathrm{EU}$, such as the capacity to maintain and improve farms (i.e. its health and genetic potential) and also the effect on human nutrition, community development and cultural issues related to the use of these livestock species (Nonhebel and Kastner, 2011). In many sheep rearing-countries, the emergence of a number of sheep parasitic infections, and inability to control them, has been reported in recent years (Taylor, 2012). This may be a reflection of alterations in sheep management and husbandry systems, climatic and environmental changes, over-reliance on anti-parasitic drugs and selection for resistance, or a function of them all (Taylor, 2012). 
Fasciola hepatica is a "well-known, old parasite of sheep" (Rojo-Vazquez et al., 2012), which continues to be a serious challenge to the health, welfare, productivity and reproduction of livestock throughout the world (Charlier et al., 2014). Due to its persistence and zoonotic role, more attention has been paid in the last few years towards this particular liver fluke. Aspects of the biology, epidemiology, diagnosis and control of F. hepatica infection in sheep have recently been reviewed (Rojo-Vazquez et al., 2012; Taylor, 2012).

Moreover, new reports on the re-emergence of fasciolosis in sheep, which are likely due to climatic changes and/or environmental modifications, suggest that the epidemiological patterns are changing with increasing prevalence in both northern (Kenyon et al., 2009; Novobilský et al., 2014) and southern European countries (Martínez-Valladares et al., 2013; Bosco et al., 2015). However, field studies on the distribution of F. hepatica in sheep are usually scattered and concerned with a single area (province, region or country). Therefore, difficulties have arisen when it comes to comparing results from different study areas, climates and management regimes, or when dealing with results derived from different surveys performed with different sampling and diagnostic procedures.
The present study is part of the EU funded GLOWORM project (http://www.gloworm.eu/) with a focus on the importance of sheep farming and the variability of climatic, environmental and ecological conditions. The aim was to elucidate the prevalence and intensity of F. hepatica infection in sheep farms across Europe by a standardized, cross-sectional survey conducted in 2012-2013 in three pilot areas of Ireland, Switzerland and Italy.

\section{Materials and methods}

\section{Study area}

Cross-sectional surveys were conducted in pilot areas in three key European countries (Fig. 1): the Sligo and Leitrim Counties in Ireland $\left(3,427 \mathrm{~km}^{2}\right)$, the cantons Zürich, Aargau, Thurgau and St. Gallen in Switzerland $\left(6,044 \mathrm{~km}^{2}\right)$ and the Campania region in Italy $\left(13,598 \mathrm{~km}^{2}\right)$. The total number of sheep farms registered in each country and in each pilot area (both in 2012 and 2013) is shown in Table 1 . In the three pilot areas small ruminant farming has a prominent role for the economy.

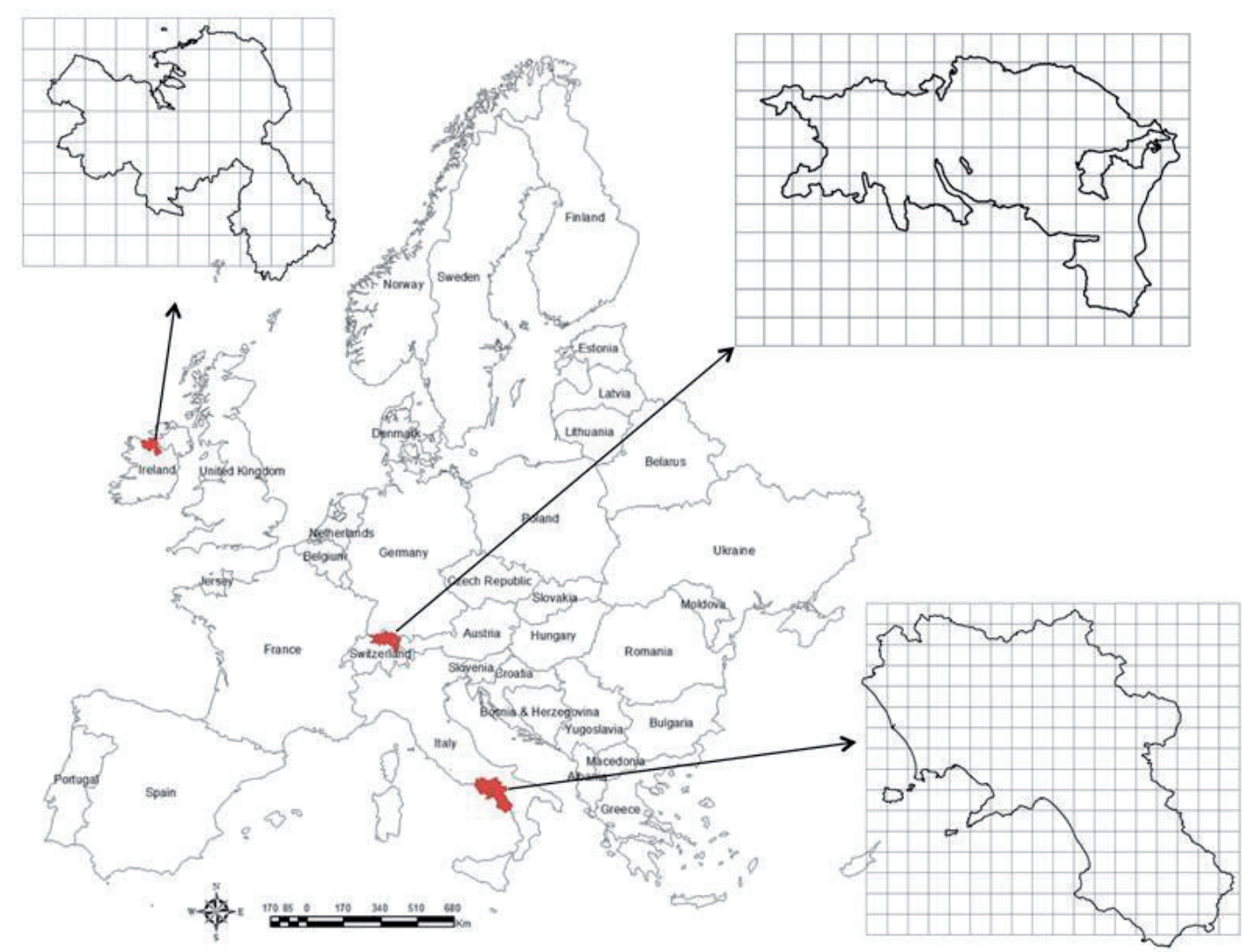

Fig. 1. Pilot areas (divided into $10 \times 10 \mathrm{~km}$ quadrants) of Ireland, Switzerland and Italy where two consecutive, cross-sectional surveys were conducted in 2012 and 2013 within the GLOWORM project. 
Study design, geographical information systems and farm sampling

Two consecutive field surveys (in 2012 and 2013) were conducted in the three countries in the same periods, i.e. during the second half of the sheep grazing season (August-October). A geographical information system (GIS), using the coordinate reference system ETRS 1989 Lambert Azimuthal Equal AreaLAEA, was developed using Arc-GIS 10.2.2 software (ESRI, Redlands, CA, USA). This was used, as reported by Musella et al. (2014), to construct a grid representing $10 \times 10 \mathrm{~km}$ quadrants that could be overlaid on each pilot area map within the GIS as shown in Fig. 1. As a result, the pilot areas in Ireland, Switzerland and Italy were divided into 57, 95 and 135 equal quadrants, respectively (Fig. 1). All the farms sampled (each coded by a specific ID) were georeferenced using digital aerial photos (Google Earth) of the pilot areas (Rinaldi et al., 2006) and knowledge of the location of farms (pastures) by veterinarians and/or agricultural advisors working in each pilot area. We designed the same uniform survey with exclusion criterion of farms with less than 20 animals and inclusion criterion of being registered in local veterinary systems. In Ireland and Italy the farms were selected from the veterinary system database and invited to participate in the GLOWORM surveys. In the case of Switzerland they were provided by the Extension and Health Service for Small Ruminants. However, the predefined farm numbers could not be met due to the non-participation of some farms in each pilot area (around 15\% in Ireland and $10 \%$ in both in Switzerland and Italy). It should be noted that, in the Campania region of southern Italy, previous surveys were used to evaluate how biased the survey sampling could be versus a systematic grid design (Musella et al., 2011, 2014). While properly conducted systematic grid sampling is straightforward in Italy, barriers to this approach exist in Ireland and Switzerland due to confidentiality and passive surveillance limitations. In the latter case, we were forced to carry out preferential sampling. In both cases, Bayesian geostatistical models taking informative/preferential sampling into account were developed (Catelan et al., 2015). A total of 361 sheep farms were tested in the three pilot areas during the two sampling periods (Table 1).

\section{Animal sampling and laboratory procedures}

For each farm, faeces were collected from 15 adult (older than 18 months) and 5 young (4-18 months) sheep (when possible). Veterinarians or farmers in each pilot area were asked to collect the samples for the surveys and were provided with a copy of the trial protocol and materials for faeces collection plus transport. Questionnaires with standard questions regarding farm management and epidemiological data were also recorded (data not shown). Once at the laboratory in each country, the samples were vacuumpacked (Rinaldi et al., 2011) and couriered to the central laboratory in Italy where they were analysed using standardized procedures. Specifically, for each farm, faecal samples were added together into 4 pools of 5 individual samples (Cringoli et al., 2002; Musella et al., 2011; Rinaldi et al., 2014). Each pooled sample was prepared, using equal amounts ( $2 \mathrm{~g}$ or less) from each individual faecal sample (Rinaldi et al., 2014). However, the predefined pool numbers could not be met when farms had less than 20 animals available for sampling, e.g. when young animals were not sampled. Hence, as can be seen in Table 3, the total number of pools examined from the 361 sheep farms was 1,079 (327 pools from young and 752 from adult sheep). For each pooled sample, faecal egg counts (FEC) were performed using the FLOTAC dual technique (Cringoli et al., 2010; Rinaldi et al., 2012) having an analytic sensitivity of 6 eggs per gram of faeces (EPG). A zinc sulphate-based flotation solution $\left(\mathrm{ZnSO}_{4}\right.$ specific gravity $=1.350$ ) was used to detect and count F. hepatica eggs (Fig. 2).

Table 1. Total number of sheep farms registered in each country and in each pilot area (2012 and 2013) of the GLOWORM project.

\begin{tabular}{|c|c|c|c|c|}
\hline \multirow{2}{*}{ Country } & \multicolumn{2}{|c|}{$\begin{array}{l}\text { Number of sheep farms } \\
\text { in the country }\end{array}$} & \multicolumn{2}{|c|}{$\begin{array}{l}\text { Number of sheep farms } \\
\text { in the pilot area and compared to the whole country }(\%)\end{array}$} \\
\hline & 2012 & 2013 & 2012 & 2013 \\
\hline Ireland ${ }^{1}$ & 34,048 & 34,304 & $2,419 \quad(7.1 \%)$ & $(7.1 \%)$ \\
\hline Switzerland ${ }^{2}$ & 9,169 & 8,903 & $2,114(23.1 \%)$ & $2,028 \quad(22.1 \%)$ \\
\hline Italy ${ }^{3}$ & 95,569 & 94,055 & $6,322 \quad(6.6 \%)$ & $(6.8 \%)$ \\
\hline
\end{tabular}

Source: ${ }^{1}$ Department of Agriculture Food and the Marine (DAFM), Ireland; ${ }^{2}$ Swiss Federal Statistical Office, Switzerland; ${ }^{3}$ National Data Bank of the Livestock Registry, Italy. 


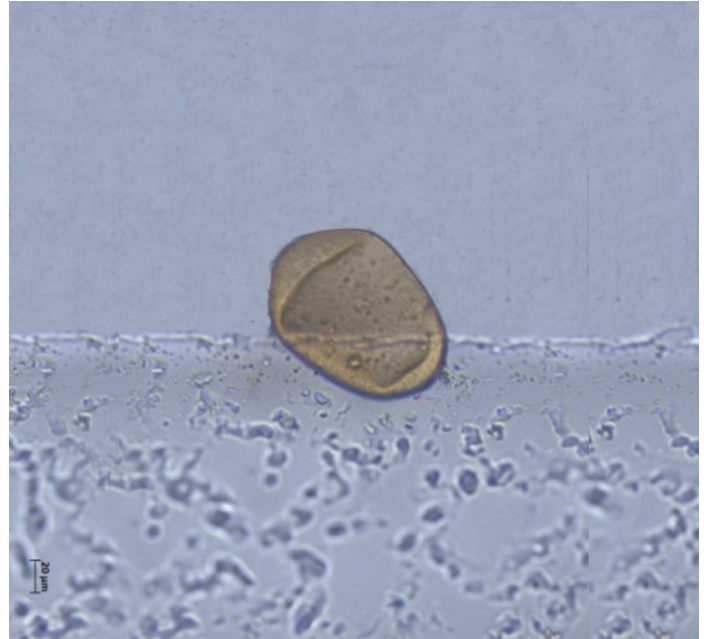

Fig. 2. Egg (slightly deformed due to flotation solution) of F. hepatica under FLOTAC (400x magnification).

\section{GIS mapping, climatic and environmental variables}

In order to display the distribution of $F$. hepatica in sheep farms located in the three pilot areas, point distribution maps were drawn (Fig. 3) within the GIS. In addition, the GIS for the study areas were implemented utilizing the climatic and environmental variables (Worldclim and MODIS datasets, http://www.worldclim.org/bioclim) as datalayers as described by
Ducheyne et al. (2015). Elevation, slope and aspect of each pilot area were obtained from a digital elevation model (DEM) with a horizontal grid spacing of 30 arcseconds (approximately $1 \mathrm{~km}$ ) (source: GTOPO30, available from U.S. Geological Survey, EROS Data Center, Sioux Falls, South Dakota, USA). Data on each of these variables were then extracted and used as 3-km diameter "buffer zones" (Cringoli et al., 2002) centred on the georeferenced sheep farms (points).

\section{Statistical methods}

Parasitological data were summarized as proportion or averages and $95 \%$ confidence intervals (CI) calculated using standard approaches. Intensity of $F$. hepat$i c a$ infection in each farm was assessed through the mean EPG calculated from positive pools. In addition, $25^{\text {th }}, 50^{\text {th }}$ and $75^{\text {th }}$ percentiles of $F$. hepatica EPG were also calculated.

Disease mapping was conducted specifying Bayesian geostatistical models based on WinBugs software (Lunn et al., 2000). However, the study design in the three areas was different from the standard approach due to the privacy restrictions mentioned above. Thus, there were two processes that had to be considered in the data analysis: the point process that governed the selection of farms and the

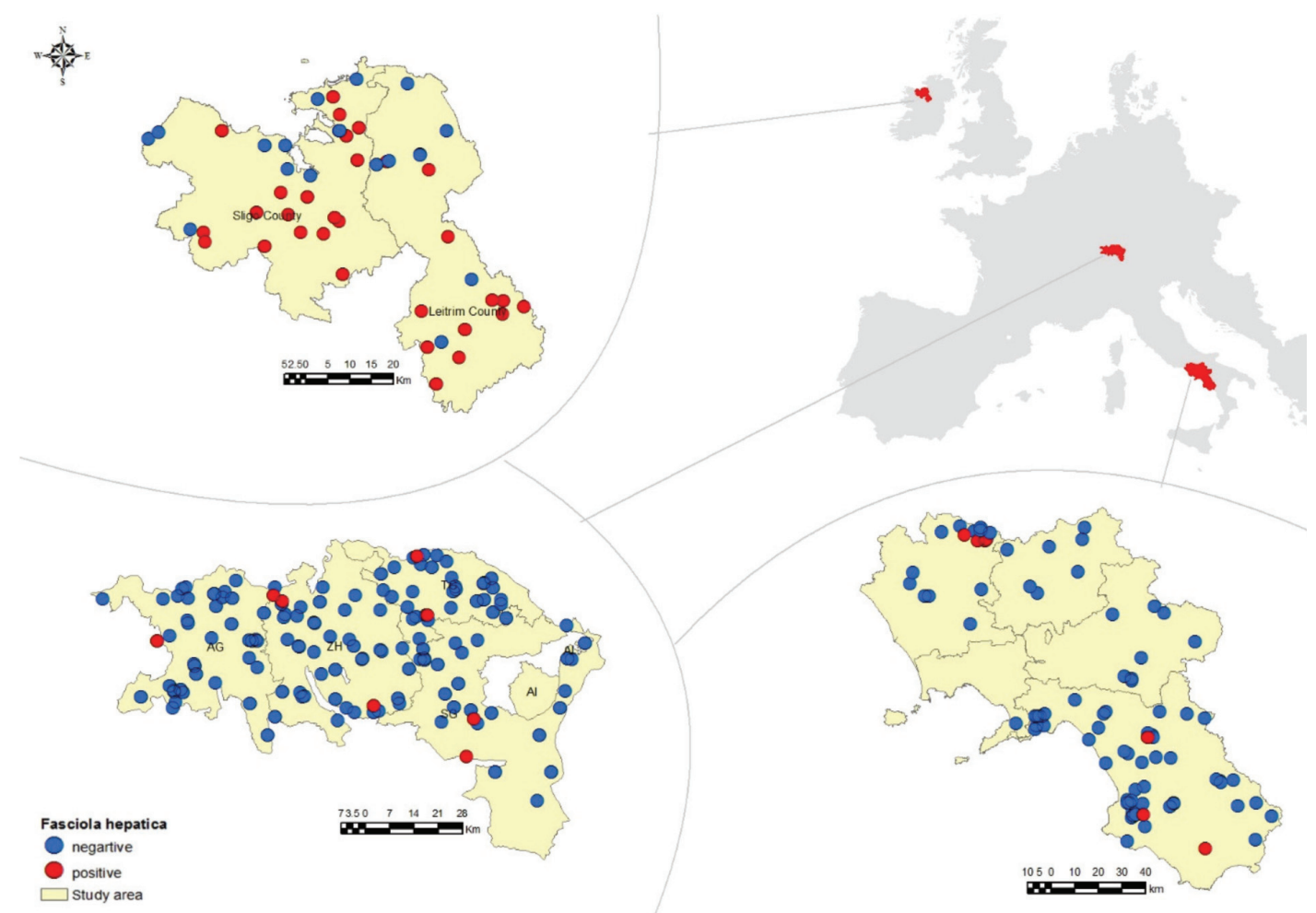

Fig. 3. Distribution of $F$. hepatica in sheep farms located in the pilot areas in Ireland, Switzerland and Italy - GLOWORM project 2012-2013. 
Table 2. Prevalence and eggs per gram (EPG) of F. hepatica in sheep farms from the studied pilot regions within the GLOWORM project in the two study years (August-October 2012 and 2013).

\begin{tabular}{|c|c|c|c|c|c|c|c|c|c|}
\hline \multirow{3}{*}{ Country } & \multirow{2}{*}{\multicolumn{3}{|c|}{$\begin{array}{l}\text { Number of } \\
\text { sampled } \\
\text { sheep farms }\end{array}$}} & \multicolumn{6}{|c|}{ Fasciola hepatica in sheep farms in the pilot areas from three European countries } \\
\hline & & & & \multicolumn{3}{|c|}{$\begin{array}{l}\text { Number of positive farms (\%) } \\
(95 \% \text { Confidence Interval) }\end{array}$} & \multicolumn{3}{|c|}{$\begin{array}{c}\text { Mean EPG } \\
\left(25^{\text {th }}-50^{\text {th }}-75^{\text {th }} \text { percentiles }\right)\end{array}$} \\
\hline & 2012 & 2013 & Total & 2012 & 2013 & Total & 2012 & 2013 & Total \\
\hline Ireland & 32 & 41 & 73 & $\begin{array}{c}22(68.8) \\
(49.9-83.3)\end{array}$ & $\begin{array}{c}23(56.1) \\
(39.9-71.2)\end{array}$ & $\begin{array}{c}45(61.6) \\
(49.5-72.6)\end{array}$ & $\begin{array}{c}18.7 \\
(3.7-6.0-14.2)\end{array}$ & $\begin{array}{c}25.6 \\
(3.6-12.0-30-0)\end{array}$ & $\begin{array}{c}22.2 \\
(3.8-7.5-26.7)\end{array}$ \\
\hline Switzerland & 73 & 126 & 199 & $\begin{array}{c}4(5.5) \\
(1.8-14.2)\end{array}$ & $\begin{array}{c}4(3.2) \\
(1.0-8.4)\end{array}$ & $\begin{array}{c}8(4.0) \\
(1.9-8.1)\end{array}$ & $\begin{array}{c}64.5 \\
(2.5-8.2-183.0)\end{array}$ & $\begin{array}{c}3.4 \\
(1.9-3.0-5.2)\end{array}$ & $\begin{array}{c}33.9 \\
(1.9-3.7-10.5)\end{array}$ \\
\hline Italy & 28 & 61 & 89 & $\begin{array}{c}3(10.7) \\
(2.8-29.4)\end{array}$ & $\begin{array}{c}4(6.6) \\
(2.1-16.8)\end{array}$ & $\begin{array}{c}7(7.9) \\
(3.5-16.1)\end{array}$ & $\begin{array}{c}25.6 \\
(6.0-21.0-45.6)\end{array}$ & $\begin{array}{c}30.2 \\
(10.0-25.0-55.0)\end{array}$ & $\begin{array}{c}27.8 \\
(10.0-21.0-48.0)\end{array}$ \\
\hline
\end{tabular}

continuous, spatial process for infection risk. Two separate, spatial random processes were specified. In step 1, a Bayesian analysis to model the spatial concentration of farm locations was performed (Diggle et al., 2010). We specified an inhomogeneous Poisson process with the count of sampled farms per grid cell and the total number of farms per grid cell as population denominator. From this model, posterior sampling probabilities per grid cell was obtained and used as weight in the geostatistical model fitted in step 2 . Here, a Bayesian weighted geostatistical model with covariates on the presence/absence of F. hepatica infection was specified. A continuous risk surface of parasitic infection in the three study areas was then predicted using information from a large number of climatic and environmental variables obtained from MODIS and GIS data as described above. We avoided a selection step and preferred to reduce the dimensionality of the problem performing a Bayesian factor analysis, including three latent factors in the geostatistical model (Musella et al., 2011). A detailed description of the weighted Bayesian geostatistical model with latent factor analysis is described by Catelan et al. (2015).

\section{Results}

\section{Observed field data}

Fig. 3 shows the distribution of F. hepatica in sheep farms tested in the three pilot areas. The observed F. hepatica prevalence differed across the different European areas showing high values in Ireland $(45 / 73=61.6 \% ; 95 \% \mathrm{CI}=49.5-72.6 \%)$ compared to Italy $(7 / 89=7.9 \% ; 95 \%$ CI $=3.5-16.1 \%)$ and Switzerland $(8 / 199=4.0 \% ; 95 \% \mathrm{CI}=1.9-8.1 \%)$. The data showed a clustered spatial distribution of positive farms in Italy and Switzerland and a north-south gradient in Ireland. Table 2 shows the number of positive farms, the prevalence (number of positive farms over the total number of farms), including the $95 \%$ CI and the intensity of F. hepatica egg excretion (mean EPG calculated on the positive pools and the $25^{\text {th }}, 50^{\text {th }}$ and $75^{\text {th }}$ percentiles) by pilot area and study year.

The observed F. hepatica prevalence did not differ between the two study years in any of the three pilot areas. Table 3 shows the specific prevalence rates of F. hepatica by age group (adults and young sheep) related to pooled samples and controlled per-cluster

Table 3. Prevalence ( $95 \%$ confidence interval) of $F$. hepatica in sheep by age (pooled samples) controlled for the cluster effect of pools within farms - GLOWORM project 2012-2013.

\begin{tabular}{lcccc}
\hline Age group & $\begin{array}{c}\text { Number of } \\
\text { pooled samples }\end{array}$ & $\begin{array}{c}\text { Number of } \\
\text { positive samples }\end{array}$ & $\begin{array}{c}\text { Expressed as } \\
\text { percent (95\% CI) }\end{array}$ & $\begin{array}{c}\text { Cluster-controlled outcome - expressed } \\
\text { as percent (95\% CI) }\end{array}$ \\
\hline Adult & 752 & 98 & $13.0(10.7-15.7)$ & $13.0(10.0-17.0)$ \\
Young & 315 & 12 & $3.8(2.1-6.7)$ & $3.7(2.0-6.9)$ \\
\hline
\end{tabular}


A

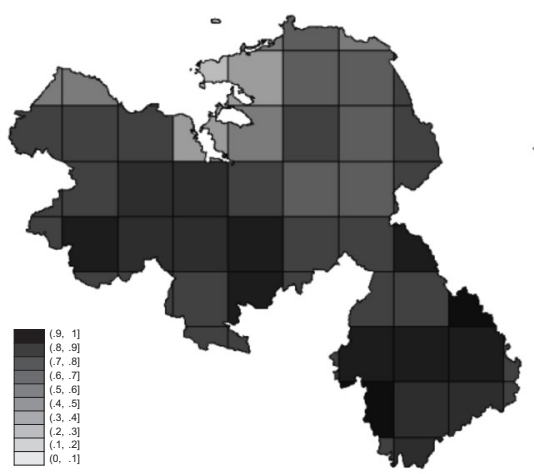

B

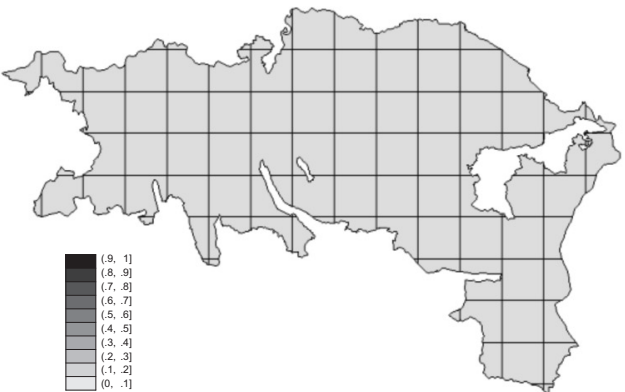

C

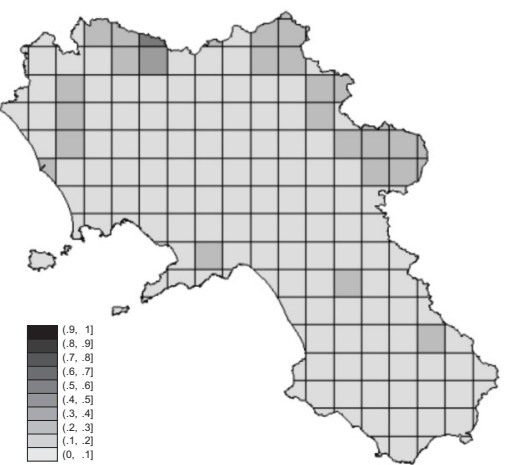

Fig. 4. Posterior predictive probability of F. hepatica infection in pilot areas in Ireland (A), Switzerland (B) and Italy (C) - GLOWORM project 2012-2013.

effect of pools within the farms. Liver fluke prevalence differed with respect to age being higher among older sheep versus younger ones (13 versus 4 ) respectively (Table 3). F. hepatica EPG in the positive pooled samples ranged from 6 to $558 \mathrm{EPG}$ in adults $\left(\right.$ mean $=48.8 ; 25^{\text {th }}, 50^{\text {th }}$ and $75^{\text {th }}$ percentiles $=6.0$, 12.0 and 43.5, respectively) and from 6 to 18 EPG in young sheep (mean $8.0 ; 25^{\text {th }}, 50^{\text {th }}$ and $75^{\text {th }}$ percentiles $=6.0,6.0$ and 10.5, respectively).

\section{Bayesian geostatistical modelling}

The georeferenced parasitological data from the 361 sheep farms in the pilot areas from Ireland, Switzerland and Italy were modelled according to a Bayesian geostatistical approach with correction for preferential sampling and accounting for GIS and remotely sensed covariates (Catelan et al., 2015). The latent factor analysis highlights the importance of year-to-year variation of the mean temperature, rain- fall and seasonality within the country, while the long-term trend of mean temperature and rainfall dominated when the country-to-country prevalence rates were compared (Caminade et al., 2015; Ducheyne et al., 2015). The posterior predictive probabilities per grid cell for the pilot areas of the three investigated countries are shown in Fig. 4. The predicted prevalence of F. hepatica was higher in Ireland with a range from $11 \%$ to $81 \%$. Fig. $4 a$ shows that there is a spatial pattern in the distribution of the parasite in Ireland with a north-south gradient. F. hepatica was very rare in the pilot areas in Italy and Switzerland with a range of posterior predictive probabilities of $0.7 \%-30 \%$ and $1.4 \%-8.6 \%$, respectively. In the pilot areas in Switzerland and Italy, the maps of the predicted probabilities were almost flat (Fig. 4 b,c).

To show the prediction uncertainty and the withinarea variability, the posterior probability for each grid cell in excess with respect to the observed mean preva-
A

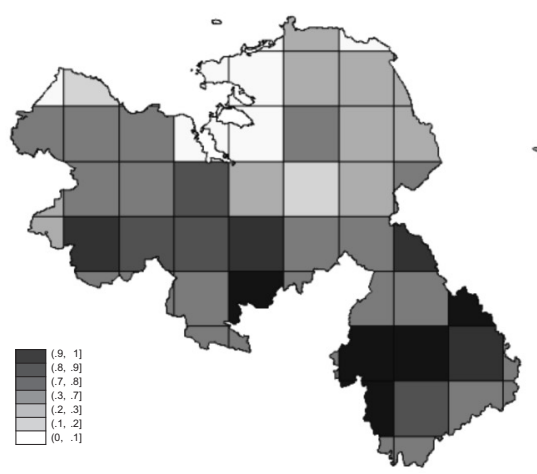

B

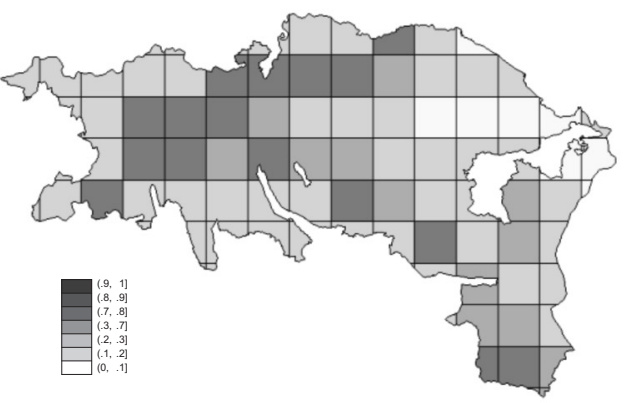

C

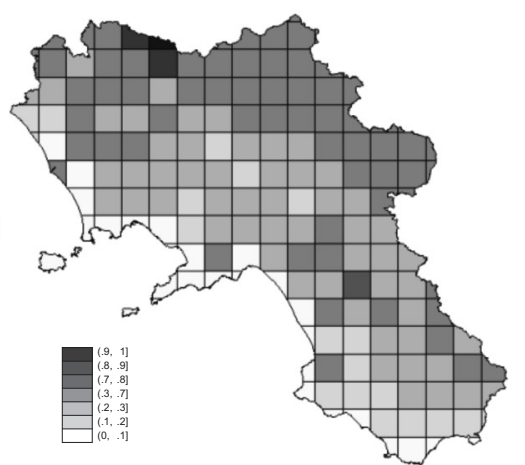

Fig. 5. Posterior probability to be in excess with respect to the average regional prevalence in pilot areas from Ireland (A), Switzerland (B) and Italy (C) - GLOWORM project 2012-2013. 
lence can be seen in Fig. 5 (64\% in Ireland, 4\% in Switzerland and $8 \%$ in Italy).

The results confirm the high prevalence of $F$. hepati$c a$ in Ireland with higher risk of infection in the southwest part (Fig. 4). Despite of the overall low predicted prevalence in the pilot areas in Switzerland and Italy. it is possible to find a few grid cells with higher than average risk of infection (Fig. 5). However, the spatial pattern was weak, posterior probabilities being higher than average were below $70 \%$ in Switzerland and above $90 \%$ only in a small cluster of three grid cells in Italy.

\section{Discussion}

To our knowledge, this is the first harmonized, cross-sectional coprological survey on the prevalence and distribution of F. hepatica in sheep across an European north-south transect, conducted with the same methodology carried out in the same timeframe. As done for cattle by Ducheyne et al. (2015) for the GLOWORM project, we collected updated and reliable parasitological data for sheep through a standardized and harmonized approach based on cost-efficient, spatial sampling and diagnostic procedures involving pooled samples (Rinaldi et al., 2011) using the highly sensitive, accurate FLOTAC technique (Cringoli et al., 2010). This approach was used in order to: (i) construct high-quality maps to be disseminated to practitioners, farmers, decision-makers and other stakeholders in each pilot area/country; and (ii) use high-quality data as input for the Bayesian geostatistical models developed (Catelan et al., 2015).

The findings of the present study showed that the overall prevalence of F. hepatica in sheep farms in Europe is around $16 \%$. However, results differed across the countries investigated showing high prevalence rates in Ireland (around 62\%) and low rates in Switzerland (around 4\%) and Italy (around 8\%). These results for Italy are consistent with the low prevalence $(1-12.4 \%)$ recently reported in sheep farms in southern Italy (Musella et al., 2011; Bosco et al., 2013). In addition, the severe outbreak of fasciolosis in sheep in southern Italy described in May 2014 by Bosco et al. (2015) indicates that changes in the epidemiology of $F$. hepatica at smaller scales could quickly occur as a consequence of climate change.

In the case of Ireland and Switzerland, only "personal communications" or "anecdotal" reports of fasciolosis in sheep exist, while systematic, cross-sectional surveys have not been performed to date. More attention has been paid in the last few years towards bovine fasciolosis in these two countries, with prevalence of $8.4-21.4 \%$ in Switzerland (Rapsch et al., 2008) and $65-82 \%$ (herds exposed to F. hepatica) in Ireland (Selemetas et al., 2015). In the case of Switzerland the differences between the Fasciola prevalences observed in sheep and cattle may be due to the different type of grassland offered to both species with consequences for the availability of the intermediate host.

The georeferenced results obtained during the harmonized surveys in the three countries were modelled (at pilot area level) following a Bayesian geostatistical approach with correction for preferential sampling and accounting for environmental covariates. Spatial patterns of $F$. hepatica distribution were clearly detected in Ireland with a high risk of infection in the southwestern part of the pilot area. While the overall predicted prevalence was low, the spatial pattern of infection in the Campania region of southern Italy was similar to previous reports (Musella et al., 2011, 2014).

It is widely accepted that spatial distribution of F. hepatica is influenced by several contributing factors (Afshan et al., 2014), which are usually inter-dependent of each other. Some papers highlight climate factors as important predictors (Caminade et al., 2015), while others emphasize environmental features, such as vegetation indices (Valencia-López et al., 2012), and/or soil type (Selemetas et al., 2014), the presence of small water bodies (De Roeck et al., 2014), a combination of environmental factors (Musella et al., 2011, 2014), herd/flock density and other management factors (Bennema et al., 2011). The present study highlights the importance of year-to-year variation of mean temperature, rainfall and seasonality in the explanation of within-country frequency of infection, while the long-term trend of mean temperature and rainfall dominated country-to-country prevalence rates.

The present surveys emphasize that the F. hepatica prevalence rates differ in relation to age, the prevalence being higher in older animals that are exposed to a higher infection pressure by F. hepatica metacercariae due to longer periods at pasture. In the present paper, we highlight the need for integrating sound epidemiological designs with standardized diagnostic tools and strategies as well as geospatial tools for mapping helminth infections of sheep across Europe (Cringoli et al., 2013). Recognizing these challenges, harmonization of sampling and laboratory procedures, along with innovating, validating and applying new strategies, will foster and sustain long-term control of F. hepatica infections of livestock in Europe (Rinaldi and Cringoli, 2014). 
In conclusion, the updated data and maps of the spatial distribution, prevalence rates of F. hepatica in European sheep has the potential to deliver improved directives with respect to the control of helminth infections for veterinarians, farmer associations and other stakeholders. The spatial sampling guidelines and the centralised GIS-based spatial data archive constructed during the GLOWORM project represents a guide for future epidemiological studies aimed at parasitological surveillance at different spatial scales.

\section{Acknowledgements}

The authors would like to express their sincere appreciation to the farmers, the veterinarians and all the staff at CREMOPAR for their technical support in the laboratories. The excellent support from Regula Giezendanner (Swiss Extension and Health Service for Small Ruminants) and Erika Perler (Research Institute for Organic Farming, Frick, Switzerland) is greatly acknowledged. The research leading to these results has received funding from the European Union Seventh Framework Programme FP7-KBBE-2011-5 under grant agreement no 288975.

\section{References}

Afshan K, Fortes-Lima CA, Artigas P, Valero AM, Qayyum M, Mas-Coma S, 2014. Impact of climate change and man-made irrigation systems on the transmission risk, long-term trend and seasonality of human and animal fascioliasis in Pakistan. Geospat Health 8, 317-334.

Bennema SC, Ducheyne E, Vercruysse J, Claerebout E, Hendrickx G, Charlier J, 2011. Relative importance of management, meteorological and environmental factors in the spatial distribution of Fasciola hepatica in dairy cattle in a temperate climate zone. Int J Parasitol 41, 225-233.

Bosco A, Rinaldi L, Musella V, Amadesi A, Cringoli G, 2015. Outbreak of acute fasciolosis in sheep farms in a Mediterranean area arising as a possible consequence of climate change. Geospat Health 9, 319-324.

Bosco A, Rinaldi L, Musella V, Pintus D, Santaniello M, Morgoglione ME, Zacometti G, Cringoli G, 2013. Helminths in sheep on farms of the Basilicata region of southern Italy. Vet Sci 17, 91-94.

Caminade C, Van Dijk J, Baylis M, Williams D, 2015. Modelling recent and future climatic suitability for fasciolosis transmission risk in Europe. Geospat Health 9, 301-308.

Catelan D, Cecconi L, Grisotto L, Biggeri A, Rinaldi L, Cringoli G. Sampling designs in veterinary parasitological surveillance. Geospat Health, in press.

Charlier J, Vercruysse J, Morgan E, van Dijk J, Williams DJ, 2014. Recent advances in the diagnosis, impact on production and prediction of Fasciola hepatica in cattle. Parasitology 141, 326-335.

Chiotti QP, Johnston T, 1995. Extending the boundaries of climate change research: a discussion on agriculture. J Rural Stud 11, 335-350.

Cringoli G, Rinaldi L, Albonico M, Bergquist R, Utzinger J, 2013. Geospatial (s)tools: integration of advanced epidemiological sampling and novel diagnostics. Geospat Health 7, 399-404.

Cringoli G, Rinaldi L, Maurelli MP, Utzinger J, 2010. FLOTAC: new multivalent techniques for qualitative and quantitative copromicroscopic diagnosis of parasites in animals and humans. Nat Protoc 5, 503-515.

Cringoli G, Rinaldi L, Veneziano V, Capelli G, Malone JB, 2002. A cross-sectional coprological survey of liver flukes in cattle and sheep from an area of the southern Italian Apennines. Vet Parasitol 108, 137-143.

De Roeck E, Van Coillie F, De Wulf R, Soenen K, Charlier J, Vercruysse J, Hantson W, Ducheyne E, Hendrickx G, 2014. Fine-scale mapping of vector habitats using very high resolution satellite imagery: a liver fluke case-study. Geospat Health 8, S671-S683.

Diggle PJ, Menezes R, Su Ting-li, 2010. Geostatistical inference underpreferential sampling. Appl Stat 59, 1-20.

Ducheyne E, Charlier J, Vercruysse J, Rinaldi L, Biggeri A, Demeler J, Brandt C, de Waal T, Selemetas N, Höglund J et al., 2015. Modeling the spatial distribution of Fasciola hepatica in dairy cattle in Europe. Geospat Health 9, 261-270.

FAOSTAT, 2012. Available at: http://faostat.fao.org/site/573/ DesktopDefault.aspx?PageID=573\#ancor (accessed on June 2014).

Kenyon F, Sargison ND, Skuce PJ, Jackson F, 2009. Sheep helminth parasitic disease in south eastern Scotland arising as a possible consequence of climate change.Vet Parasitol 26, 293-297.

Lunn DJ, Thomas A, Best N, Spiegelhalter D, 2000. WinBUGS - a Bayesian modelling framework: concepts, structure, and extensibility. Stat Comput 10, 325-337.

Martínez-Valladares M, Robles-Pérez D, Martínez-Pérez JM, Cordero-Pérez C, Famularo Mdel R, Fernández-Pato N, González-Lanza C, Castañón-Ordóñez L, Rojo-Vázquez FA, 2013. Prevalence of gastrointestinal nematodes and Fasciola hepatica in sheep in the northwest of Spain: relation to climatic conditions and/or man-made environmental modifications. Parasit Vectors 27, 282.

Morgan ER, Charlier J, Hendrickx G, Biggeri A, Catelan D, von Samson-Himmelstjerna G, Demeler J, Müller E, van Dijk J, Kenyon F, Skuce P, Höglund J, O'Kiely P, van Ranst B, de Waal T, Rinaldi L, Cringoli G, Hertzberg H, Torgerson P, Wolstenholme A, Vercruysse J, 2013. Global change and helminth infections in grazing ruminants in Europe: impacts, trends and sustainable solutions. Agriculture 3, 484-502. 
Musella V, Catelan D, Rinaldi L, Lagazio C, Cringoli G, Biggeri A, 2011. Covariate selection in multivariate spatial analysis of ovine parasitic infection. Prev Vet Med 99, 69-77.

Musella V, Rinaldi L, Lagazio C, Cringoli G, Biggeri A, Catelan D, 2014. On the use of posterior predictive probabilities and prediction uncertainty to tailor informative sampling for parasitological surveillance in livestock. Vet Parasitol 205, 158-168.

Nonhebel S, Kastner T, 2011. Changing demand for food, livestock feed and biofuels in the past and in the near future. Livest Sci 139, 3-10.

Novobilský A, Engström A, Sollenberg S, Gustafsson K, Morrison DA, Höglund J, 2014. Transmission patterns of Fasciola hepatica to ruminants in Sweden. Vet Parasitol 203, 276-286.

Park YW, Haenlein GFW, 2006. Handbook of Milk of NonBovine Mammals. Blackwell Publishing, Ames, Iowa, USA/Oxford, UK, 449 pp.

Rapsch C, Dahinden T, Heinzmann D, Torgerson PR, Braun U, Deplazes P, Hurni L, Bär H, Knubben-Schweizer G, 2008. An interactive map to assess the potential spread of Lymnaea truncatula and the free-living stages of Fasciola hepatica in Switzerland. Vet Parasitol 154, 242-249.

Rinaldi L, Coles GC, Maurelli MP, Musella V, Cringoli G, 2011. Calibration and diagnostic accuracy of simple flotation, McMaster and FLOTAC for parasite egg counts in sheep. Vet Parasitol 177, 345-352.

Rinaldi L, Cringoli G, 2014. Exploring the interface between diagnostics and maps of neglected parasitic diseases. Parasitology 28, 1-8.
Rinaldi L, Gonzalez S, Guerrero J, Aguilera LC, Musella V, Genchi C, Cringoli G, 2012. A One-Health integrated approach to control fascioliasis in the Cajamarca valley of Peru. Geospat Health 6, S67-S73.

Rinaldi L, Levecke B, Bosco A, Ianniello D, Pepe P, Charlier J, Cringoli G, Vercruysse J, 2014. Comparison of individual and pooled faecal samples in sheep for the assessment of gastrointestinal strongyle infection intensity and anthelmintic drug efficacy using McMaster and Mini-FLOTAC. Vet Parasitol 205, 216-223.

Rinaldi L, Musella V, Biggeri A, Cringoli G, 2006. New insights into the application of geographical information systems and remote sensing in veterinary parasitology. Geospat Health 1 , 33-47.

Rojo-Vázquez FA, Meana A, Valcárcel F, Martínez-Valladares M, 2012. Update on trematode infections in sheep. Vet Parasitol 189, 15-38.

Selemetas N, Ducheyne E, Phelan P, O'Kiely P, Hendrickx G, de Waal T, 2015. Spatial analysis and risk mapping of Fasciola hepatica infection in dairy herds in Ireland. Geospat Health 9, 281-291.

Selemetas N, Phelan P, O'Kiely P, de Waal T, 2014. Weather and soil type affect incidence of fasciolosis in dairy cow herds. Vet Rec 175, 371.

Taylor MA, 2012. Emerging parasitic diseases of sheep. Vet Parasitol 189, 2-7.

Valencia-López N, Malone JB, Carmona CG, Velásquez LE, 2012. Climate-based risk models for Fasciola hepatica in Colombia. Geospat Health 6, S67-S85. 